\title{
Evaluation of Some Path Reduction Factor Models Performance in Tropical Location
}

\author{
Joseph Mom, Soo Tyokighir, Gabriel Igwue
}

\begin{abstract}
Performance evaluation of the ITU-R. P.530-17, Ghiani and Budalal model are considered for this work. It is found that the predicted values from the ITU-R and Ghiani distance factor models are seen to gradually decrease with an increase in path length for distances below $1 \mathrm{~km}$. Results further suggest that for a link length of $300 \mathrm{~m}$, the Ghiani model predicts a $0.2499 \mathrm{~dB}(1.059$ w) to $0.3273 \mathrm{~dB}(1.078$ w) precipitation loss across all four (4) stations. For the ITU-R. P.530-17 model, a $3.4741 \mathrm{~dB}(2.225$ w) to $5.329 \mathrm{~dB}$ (3.411 w) precipitation loss is estimated across all stations while the Budalal model estimated a $2.8608 \mathrm{~dB}(1.932$ w) to $4.6250 \mathrm{~dB}(2.901$ w) precipitation loss across all stations. The ITU-R. P.530-17, Ghiani and Budalal model further suggest a precipitation loss in the Received Signal Strength (RSS) of a typical 5G base station operating in the four (4) stations considered to be at least $-9.4733 \mathrm{dBm},-8.8601 \mathrm{dBm}$, and $-6.2489 \mathrm{dBm}$ respectively. Generally, all models are found to predict rain attenuation and distance factor values with disparities especially for link lengths above $300 \mathrm{~m}$. Further research is recommended on the models for accurate prediction and improve agreement with measured values.
\end{abstract}

Keywords: 5G, Distance factor, Precipitation loss, Performance evaluation.

\section{INTRODUCTION}

$\mathrm{D}_{\text {ata requirements from users across the world have }}$ tremendously increased over recent years hence the need for larger bandwidth and increase in speed of connectivity whilst maintaining the appreciable quality of service. 5th Generation (5G) networks are candidate solutions that provide efficient millimeter-wave (mmWave) spectrum utilization and high data speeds. Precipitation poses a threat to such mmWave communication links [1]. Higher frequencies especially from $7 \mathrm{GHz}$ pose deleterious effects to mm-wave links. To establish reliable 5G network links, precipitation fade studies become necessary [2], [3]. A higher rain rate, increase in path length and transmission frequency between a transmitter and receiver are key factors to be considered in 5G network design and planning. To meet the quality of service demands for mmWave links, the effect of attenuation due to rain cannot be ignored especially for

Manuscript received on September 06, 2021.

Revised Manuscript received on September 14, 2021.

Manuscript published on September 30, 2021.

* Correspondence Author

J.M. Mom, Department of Electrical and Electronics Engineering, Joseph Sarwuan Tarka University, Makurdi, Nigeria.. Email: joseffmom@gmail.com

S.S. Tyokighir*, Department of Electrical and Electronics Engineering, Joseph Sarwuan Tarka University, Makurdi, Nigeria.. Email: tyokighir.soo@uam.edu.ng

G.A. Igwue, Department of Electrical and Electronics Engineering, Joseph Sarwuan Tarka University, Makurdi, Nigeria.

(c) The Authors. Published by Blue Eyes Intelligence Engineering and Sciences Publication (BEIESP). This is an open access article under the CC BY-NC-ND license (http://creativecommons.org/licenses/by-nc-nd/4.0/) distances below $1 \mathrm{~km}$ [4], [5], [6]. Several models for estimation of attenuation due to rain have been proposed with emphasis on the effective path length and considered path reduction factors less than 1 as the main part of the rain fade estimation [7], [8]. The prediction models are used to average out the spatial inhomogeneity of rain rate that is uniformly distributed along the propagation path of $1 \mathrm{~km}$ and named as specific attenuation [9], [10], [11], [12]. From the study carried out by [13], it is seen that the path reduction factors employed in an effective rain rate model may not work with a path length of less than 700 meters (m). Furthermore, studies from [14], [15] show that the path reduction statistical prediction models provide good prediction accuracy with lower mmWave bands such as $26 \mathrm{GHz}$ and $38 \mathrm{GHz}$ for path lengths longer than 1 kilometer $(\mathrm{km})$. However, for path lengths not exceeding $1 \mathrm{~km}$, the performance of most models has proven inaccurate [16], [17], [18], [19]. It can be concluded that the path reduction factor value during precipitation events is the essential yardstick to evaluate the performance of mmWave communication links.

\section{PATH REDUCTION FACTOR MODELS}

\section{A. ITU-R P.530-17 model}

The model described in [12] is based on a distance factor denoted $r$ which relies on the point rain rate $R_{0.01}$, frequency, link length, and power-law relationship coefficients of the specific attenuation. The steps are outlined from equations (1) to (6).

$$
\gamma R_{0,01}=k R_{0,0196}^{\alpha}
$$

Where,

$\mathrm{k}$ and $\propto$ are obtained using Recommendation ITU-R P.838-3 and point rainfall rate with one minute integration time $\left(R_{0,011}\right)$ obtained using the approach described in [20]. The distance factor $r$ is obtained as follows:

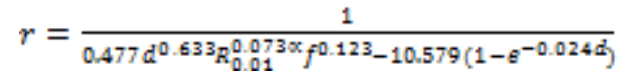

where,

$\mathrm{f}$ and $\mathrm{d}$ are the frequency and actual path length respectively. With $\propto$ given as 1.1825 from recommendation ITU-R P.838-3. The attenuation for $0.01 \%$ of the time is given as:

$$
A_{0.01}=\gamma R d_{\text {eff }}=\gamma R d r
$$

where,

$d_{\text {eff }}$ is the effective path length given as follows:

$$
d_{\text {eff }}=d r \quad(\mathrm{~km})
$$

And,

$\gamma R_{0,01}$ is obtained from Equation (1).

Attenuation for other percentages of time $p$ for the range $0.001 \%$ to $1 \%$ is given by the following power law: 


$$
\begin{aligned}
& \frac{A_{p}}{A_{0.01}}=C_{1} P^{-\left(C_{2}+C_{3} \log _{10} p\right)} \\
& \text { where, } \\
& C_{1}=\left(0.07^{C_{0}}\right)\left[0.12^{\left(1-C_{0}\right)}\right] \\
& C_{2}=0.855 C_{0}+0.546\left(1-C_{0}\right) \\
& C_{\mathrm{a}}=0.139 C_{0}+0.043\left(1-C_{0}\right) \\
& \text { And, } \\
& C_{0}=\left\{\begin{array}{cl}
0.12+0.4\left[\log _{10}(f / 10)^{0.8}\right] & f \geq 10 \mathrm{GHz} \\
0.12 & f<10 \mathrm{GHz}
\end{array}\right.
\end{aligned}
$$

\section{B. The Ghiani model}

The model described in [10] is based on the Multi EXCELL rain simulation. Attenuation due to rain is calculated using the numerical approach for a rain field size $1 \mathrm{~km} \times 1 \mathrm{~km}$ to $250 \mathrm{~km} \times 250 \mathrm{~km}$. The steps in the model are given from equations (7) to (11) as follows:

$$
r=\frac{A}{\left(k R_{T X}^{\mathrm{X}} L_{s l a n t}\right)}
$$

The correctional factor $r$ depends only on calculated attenuation, specific attenuation conversion coefficients, measured rain rates at the transmitter side, and the link length.

The attenuation due to rain is given as:

$$
A=k R_{T X}^{\alpha} L P F
$$

Where,

$\mathrm{k}$ and $\propto$ are obtained from [11].

$$
P F_{a v}=a(f, L) e^{-b(f, L) R}+c(f, L)
$$

Where,

$a, b$ and $c$ are obtained from regression coefficients which depend on the frequency and link length. Because the effect of frequency is negligible, we have:

$$
\begin{aligned}
& A(P, L)=k R(P)^{\alpha} L\left[a(L) e^{-b(L) R}+c(L)\right] \\
& \text { Where, } \\
& \qquad \begin{aligned}
a & =-0.8743 e^{-0.1111 R}+0.9061 \\
b & =-0.0931 e^{-0.0182 R}+0.1002 \\
c & =-0.661 e^{-0.178 R}+0.3965
\end{aligned}
\end{aligned}
$$

\section{The Budalal model}

The model proposed by [21] is based on the measured attenuation of smaller than $1 \mathrm{~km}$ terrestrial link and frequency of 26/38 GHz. Due to inconsistencies found on the ITU-R P.530-17 Model for link lengths below $1 \mathrm{~km}$, a modification to the distance factor proposed by the ITU-R was proposed as follows:

$$
I_{f Y}=r= \begin{cases}{\left[\frac{1}{1.77 d^{0.77} R_{0.01}^{-0.05}}\right]} & f \leq 40 G H z \\ {\left[\frac{1}{0.477 d^{0.633} R_{0.01}^{0.073} f^{0.123}}\right]^{2}} & f>40 G H z\end{cases}
$$

Hence to improve the performance of the ITU-R P.530-17 model for short-range terrestrial link communications, the parameter $I_{f Y}$ proposed in equation (12) is recommended. The attenuation for $0.01 \%$ of the time is given in equation (13) as:

$$
A_{0.01}=k R_{0.01}^{\infty} \times I_{f \gamma} \times d \mathrm{~dB}
$$

Where,

Specific attenuation $k R_{0,01}^{\infty}$ is obtained from the procedure in Equation (1) and $d$ is the link length.

\section{RESULTS AND DISCUSSION}

From recommendation ITU-R P.530-17, a path reduction factor $r$ should not exceed 2.5. However, from the findings of [7], [8], [15], [17], the distance factor exceeds this threshold value of 2.5 at path lengths less than 300 meters making the effective path length value much greater than the actual path length causing errors in the prediction of attenuation due to rain for millimeter-wave communication links. The model in [21] addresses the issue by introducing a specific attenuation constant denoted $I_{f Y}$ for the modification of the distance factor model proposed by [12]. Several other models have been developed by authors for the prediction of rain attenuation prediction based on the distance factor for millimeter-wave links. However, deviations exist between the actual measurements and theoretical predictions. This is partly a result of additional attenuation resulting from wet antenna losses which are not accounted for in such models [7], [8], [22]. The need for in-depth analysis of the performance of distance factor-based attenuation prediction models in tropical locations becomes necessary. The reduction factors proposed by [10], [12], [21] are investigated based on equations (2), (7), and (12), and results are shown in Figures (1a)-(1d). From Figure (1a), the estimated path reduction values obtained from the Ghiani model are almost constant with the value 0.357 for a link distance ranging from $800 \mathrm{~m}$ to $1 \mathrm{~km}$ across all four (4) stations. For a distance of $500 \mathrm{~m}$ to $700 \mathrm{~m}$, the path reduction factor $r$ averaged out at 0.2405. Furthermore, Fig. 1a, Fig. 1b, Fig. 1c and Fig. 1d show that the ITU-R P.530-17 model reduction factor value gradually decreases with an increase in path length while the Budalal model shows the value of reduction factor exponentially decreasing with an increase in the path length.

For the $1 \mathrm{~km}$ link length, the $r$-value ranges between 1.0688 to 1.1082 , and for the Budalal model, the $r$-value ranges from 0.7049 to 0.7178 across all stations.

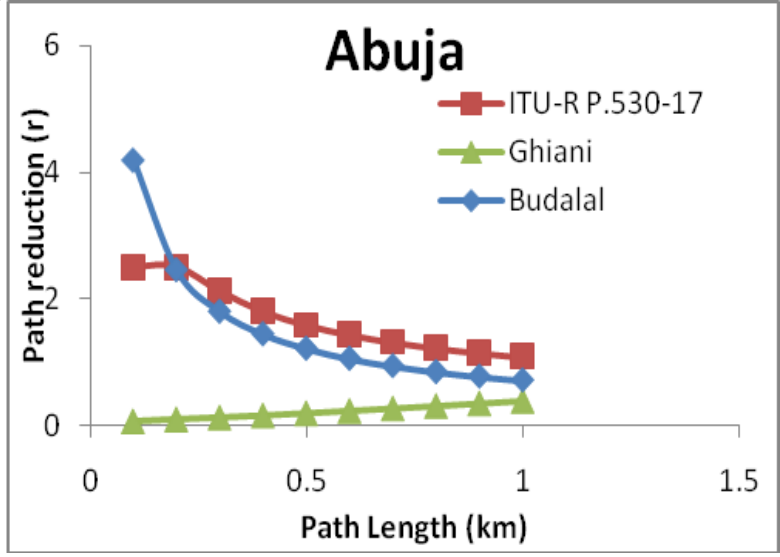

Fig. 1a: Path reduction vs. path length for Abuja

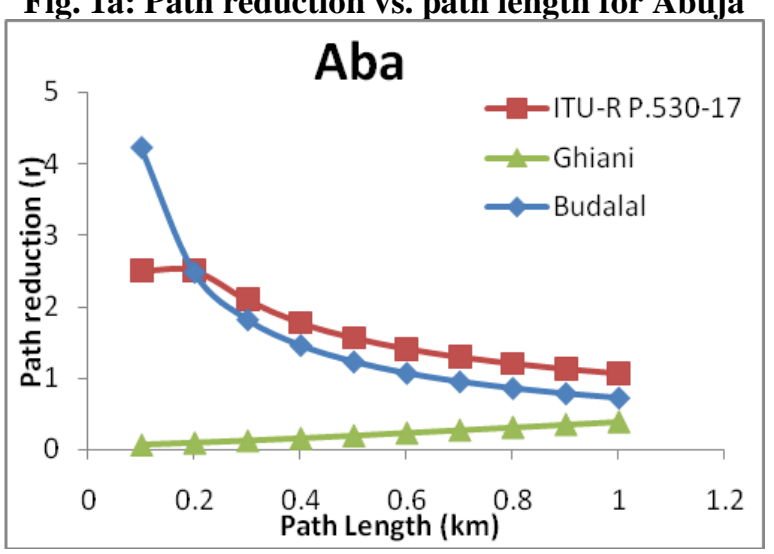

Fig. 1b: Path reduction vs. path length for Aba

Published By:

Blue Eyes Intelligence Engineering and Sciences Publication (BEIESP)

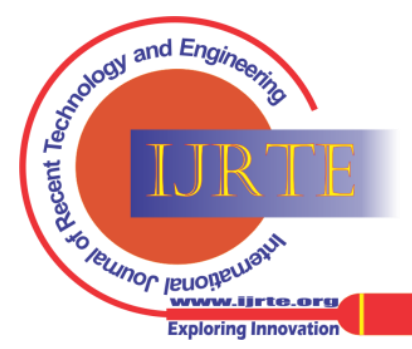




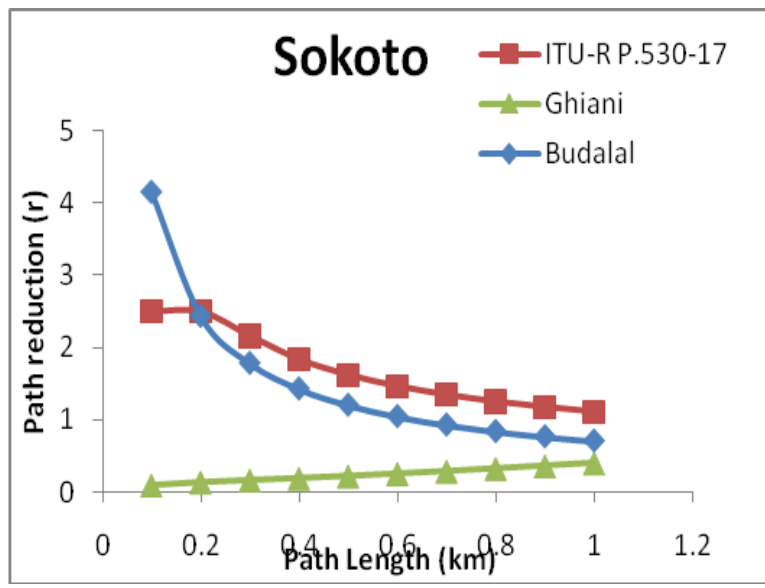

Fig. 1c: Path reduction vs. path length for Sokoto Both the ITU-R P. 530-17 and Budalal model values showed that an increase in link distance leads to a decrease in the path reduction factor $(r)$ hence causing an increase in overall attenuation. In the case of the Ghiani model, an increase in link distance leads to an increase in overall attenuation. The Ghiani model predicted distance factor values which ranged from 0.396 to 0.713 across all stations showing considerable differences when compared to the values obtained from the ITU-R P.530-17 and Budalal model.

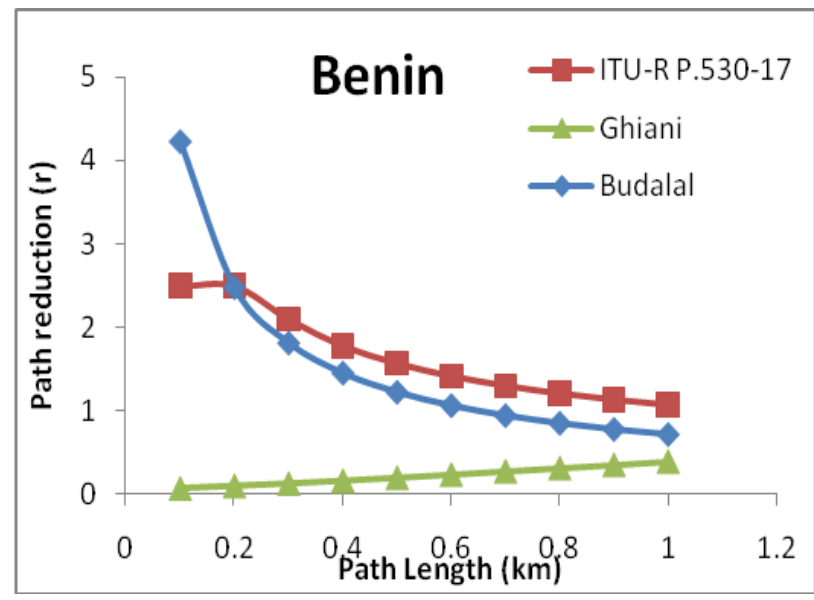

Fig. 1d: Path reduction vs. path length for Benin

\section{A. Variation of $\boldsymbol{r}$ for link lengths less than $\mathbf{3 0 0} \mathbf{~ m}$}

The reduction factor $r$ proposed by [10], [12], and [21] are investigated based on equations (2), (7), and (12) for shorter distances of $300 \mathrm{~m}$ and are represented in Fig. 1a, Fig. 1b, Fig. 1c, and Fig. 1d. From Fig. 1a to Fig. 1d, it is observed that the Ghiani, ITU-R P.530-17 and Budalal model predicted reduction factor values which ranged between $0.1285-0.1556, \quad 2.0928-2.1631, \quad$ and $1.7812-1.8163$ respectively across all stations. For a link length of $100 \mathrm{~m}$, the value of $r$ is 2.5 for the ITU-R P.530-17 model, 0.0758 for the Ghianni model, and 4.22 for the Budalal model. Considering the link distance of $300 \mathrm{~m}$ which is the maximum range for most 5G base stations, the ITU-R P.530-17, Budalal and Ghiani model had an estimated maximum reduction factor value of $2.1631,1.8163$, and 0.1556 respectively across all stations while an $r$ average value of 0.122 was recorded for link distance of $100 \mathrm{~m}$ to $300 \mathrm{~m}$.

\section{B. Rainfall rate and attenuation measurement}

The annual rainfall rate for the four stations was obtained from the Tropical Rainfall Measurement Mission (TRMM) data and validated with the Nigerian Metrological Agency (NiMet). The average annual distribution of rain rate

observations for the 20 years for the four regions is shown in Table (1)

The rain rates are given with a percentage of time year).

The percentage unavailability for $0.01 \%$ was estimated using the approach in [20] given as:

$$
R_{0,01}(\mathrm{~mm} / \mathrm{h})=\propto M^{\beta}
$$

$R_{0.01}$ is the point rain intensity at $0.01 \%$ time exceedance. $M$ is the mean annual rain accumulation while $\alpha$ and $\beta$ are regression coefficients given as 12.2903 and 0.2973 respectively.

Table- I: Station comparison of derived one-min rain rates

\begin{tabular}{|l|l|l|l|}
\hline Region & NiMet (A) & TRMM (B) & Rain gauge (C) \\
\hline Abuja 1 & 113.0 & 105.6 & 121.7 \\
\hline Abuja 2 & 111.7 & 103.2 & 118.0 \\
\hline Abuja 3 & 113.4 & 106.5 & 102.9 \\
\hline Sokoto 1 & 81.5 & 83.4 & 79.0 \\
\hline Sokoto 2 & 85.6 & 82.5 & 82.0 \\
\hline Sokoto 3 & 81.0 & 83.4 & 74.2 \\
\hline Benin 1 & 112.8 & 118.2 & 100.0 \\
\hline Benin 2 & 112.0 & 118.0 & 119.7 \\
\hline Benin 3 & 110.7 & 119.5 & 94.5 \\
\hline Aba 1 & 116.0 & 123.3 & 104.0 \\
\hline Aba 2 & 109.5 & 123.0 & 109.5 \\
\hline Aba 3 & 116.7 & 121.8 & 114.3 \\
\hline
\end{tabular}

Table- II: Mean deviation from one-minute rain rate

\begin{tabular}{|l|c|c|c|}
\hline Station & $\begin{array}{l}\text { Mean: station } \\
(\mathrm{A}) \text { and }(\mathrm{B})\end{array}$ & $\begin{array}{l}\text { Mean: station } \\
(\mathrm{B}) \text { and }(\mathrm{C})\end{array}$ & $\begin{array}{l}\text { Mean: station } \\
(\mathrm{A}) \text { and }(\mathrm{C})\end{array}$ \\
\hline Abuja & 7.566 & 9.083 & -1.516 \\
\hline Sokoto & -0.393 & -4.706 & 4.313 \\
\hline Benin & -6.733 & -13.82 & 7.086 \\
\hline Aba & -8.603 & -13.407 & 4.803 \\
\hline
\end{tabular}

Table- III: Correlation of derived one-minute rain rate

\begin{tabular}{|l|c|c|c|}
\hline Station & $\begin{array}{l}\text { Correlation } \\
\text { coefficient of } \\
\text { (A) and (B) }\end{array}$ & $\begin{array}{l}\text { Correlation } \\
\text { coefficient of } \\
\text { (B) and (C) }\end{array}$ & $\begin{array}{l}\text { Correlation coefficient } \\
\text { of } \\
\text { (A) and (C) }\end{array}$ \\
\hline Abuja & 0.999 & -0.565 & -0.539 \\
\hline Sokoto & -0.9932 & -0.781 & 0.849 \\
\hline Benin & -0.875 & -0.749 & 0.335 \\
\hline Aba & -0.431 & -0.925 & 0.054 \\
\hline
\end{tabular}

The Chebil model is used for the determination of point rainfall rates for the stations under observation in this study. The overall mean deviation and correlation coefficients of the erived rainfall rates between the Nigerian Meteorologica Agency (NiMet), Private rain gauge experiments, and the Tropical Rainfall Measurement Mission (TRMM) data are shown in Table (2) and Table (3) respectively The correlation coefficients for Abuja, Sokoto, Benin, and Aba is 0999, $-0.9932,-0.875$ and -0.431 respectively while with that of TRMM borne data and rain gauge experiments for Abuja, Sokoto, Benin, and Aba is $-0.565,-0.781,-0.749$ and -0.925 .

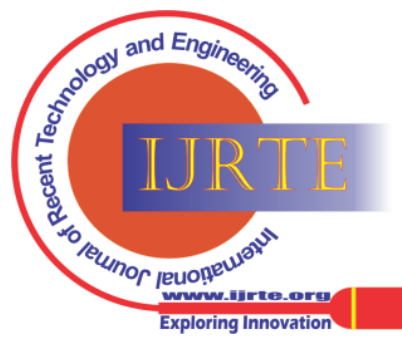


From the results obtained, disparities are seen to exist hence the need for more experiments and longer-term data to smoothen out the large variations and improve agreement. The precipitation intensity rate $R_{0.01}$ can now be seen as a key factor specification for the estimation of attenuation in decibel $(\mathrm{dB})$ for a link at particular locations The propagation measurements were carried out by NiMet and TRMM borne data as shown in Table - I.

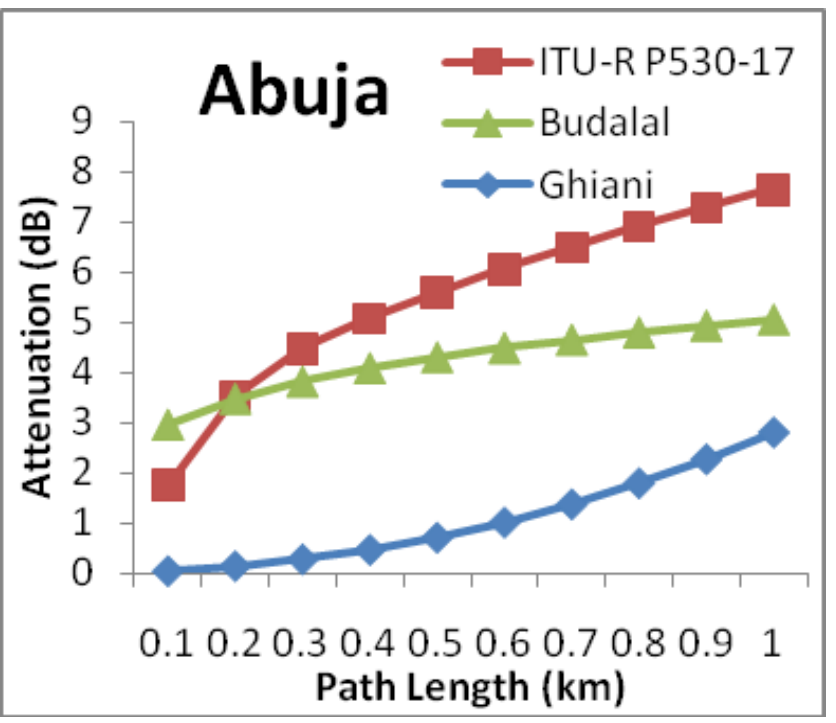

Fig. 2a: Rain attenuation vs. Path length for Abuja

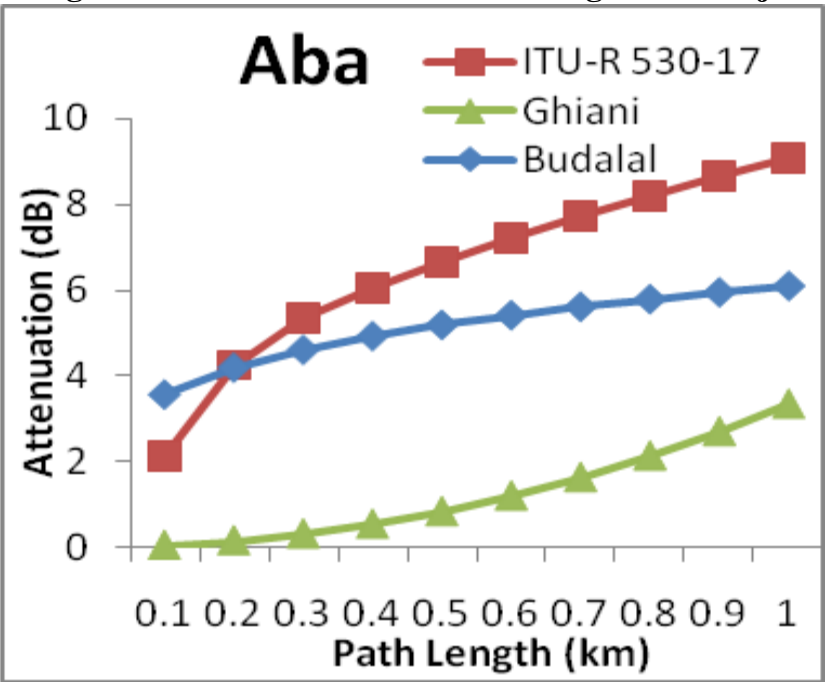

Fig. 2b: Rain attenuation vs. Path length for Aba

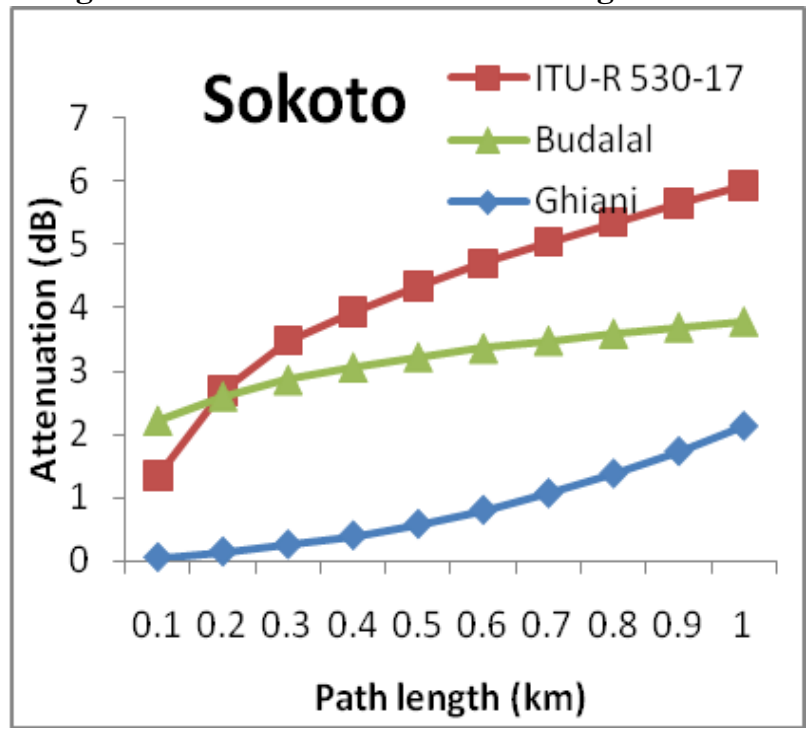

Fig. 2c: Rain attenuation vs. Path length for Sokoto

Retrieval Number: 100.1/ijrte.C64410910321

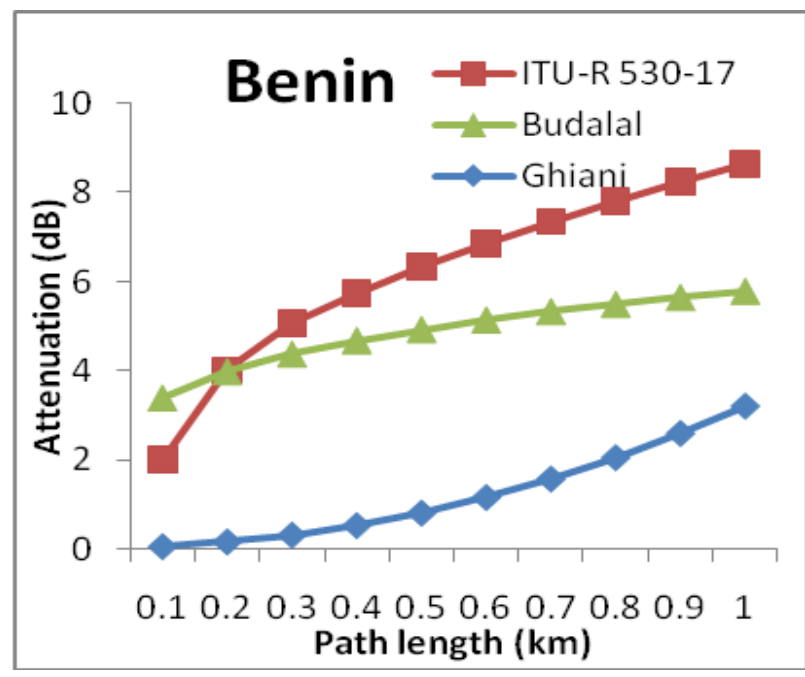

Fig. 2d: Rain attenuation vs. Path length for Benin From Table - I, considering Nigeria's NIGCOMSAT-1R earth station (Abuja), the TRMM data and NiMet data both underestimated the measured rain rate at $0.01 \%$ of time by $16.08 \mathrm{~mm} / \mathrm{h}$ and $8.73 \mathrm{~mm} / \mathrm{h}$ respectively. The rain attenuation values are shown in Fig. 2a, Fig. 2b, Fig. 2c and Fig. 2d are predicted using the ITU-R P.530-17, Budalal, and Ghiani model and are based on equations (3), (10) and (13). The measured rain rate at $R_{0.0196}$ (one-minute time integration) for Abuja, Benin, Sokoto, and Aba are 105.65 $\mathrm{mm} / \mathrm{h}, 118.19 \mathrm{~mm} / \mathrm{h}, 83.48 \mathrm{~mm} / \mathrm{h}$, and $123.27 \mathrm{~mm} / \mathrm{h}$ respectively. Path lengths considered ranged from $100 \mathrm{~m}$ to 1 $\mathrm{km}$. The frequency considered is $24.25 \mathrm{GHz}$ and horizontal antenna polarization. The predicted attenuations are compared with each of the selected models for the path lengths ranging up to $1 \mathrm{~km}$.

\section{Variation of attenuation and received signal strength for a $300 \mathrm{~m}$ link length}

Since the maximum range for most $5 \mathrm{G}$ base stations is 300 $\mathrm{m}$ it is important to determine the received signal loss attributed to precipitation for communication links across such distances. From Fig. 2a, Fig. 2b, Fig. 2c and Fig. 2d, while considering a link length of $300 \mathrm{~m}$, the Ghiani model predicts a $0.2499 \mathrm{~dB}(1.059 \mathrm{w})$ to $0.3273 \mathrm{~dB}(1.078 \mathrm{w})$ loss across all four (4) stations. For the ITU-R. P.530-17 model, a $3.4741 \mathrm{~dB}(2.225 \mathrm{w})$ to $5.329 \mathrm{~dB}(3.411 \mathrm{w})$ loss is predicted for all stations while the Budalal model estimated a 2.8608 $\mathrm{dB}(1.932 \mathrm{w})$ to $4.6250 \mathrm{~dB}(2.901 \mathrm{w})$ loss across all stations. From the results obtained, it is seen that the ITU-R. P.530-17, Ghiani and Budalal model suggest a loss in the Received Signal Strength (RSS) of at least $-9.4733 \mathrm{dBm},-8.8601 \mathrm{dBm}$, and -6.2489 respectively.

\section{Variation of attenuation and received signal strength for a $1 \mathrm{~km}$ link length}

From Fig. 2a, Fig. 2b, Fig. 2c, and Fig. 2d, a link length of $1 \mathrm{~km}$ resulted in attenuation ranging $2.1287 \mathrm{~dB}(1.633 \mathrm{w})$ to $3.3655 \mathrm{~dB}(2.17 \mathrm{w})$ for the Ghiani model. However, the ITU-R. P. 530-17 and Budalal model estimated attenuation ranging from $5.9328 \mathrm{~dB}(3.92 \mathrm{w})$ to $9.0718(8.076 \mathrm{w})$ and $3.7734 \mathrm{~dB}(2.384 \mathrm{w})$ to $6.1006 \mathrm{~dB}(4.074 \mathrm{w})$ respectively.

Published By:

Blue Eyes Intelligence Engineering and Sciences Publication (BEIESP) 114 (C) Copyright: All rights reserved.

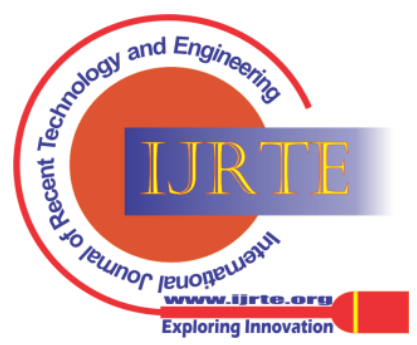


An RSS loss of at least $-8.1298 \mathrm{dBm},-11.9328 \mathrm{dBm}$, and $-9.773 \mathrm{dBm}$ is expected on the $1 \mathrm{~km}$ link based on the ITU, Ghiani, and Budalal model predictions respectively. From Fig. 2a, it is seen that the predicted attenuation at 500 meters by ITU-R P. 530-17 was $5.61 \mathrm{~dB}, 6.64 \mathrm{~dB}, 4.34 \mathrm{~dB}$, and 6.34 $\mathrm{dB}$ for Abuja, Aba, Sokoto, and Benin stations respectively. The Ghiani model shows very low predicted attenuation values of $0.717 \mathrm{~dB}, 0.85 \mathrm{~dB}, 0.57 \mathrm{~dB}$, and $0.81 \mathrm{~dB}$ for Abuja, Aba, Sokoto, and Benin stations. However, the values of 4.3 $\mathrm{dB}, 5.2 \mathrm{~dB}, 3.22 \mathrm{~dB}$, and $4.94 \mathrm{~dB}$ were predicted by the Ghiani model for Abuja, Aba, Sokoto, and Benin stations respectively. None of the predictions reflects similarity at 500 $\mathrm{m}$ path length. Since most $5 \mathrm{G}$ base stations transmit power up to $24 \mathrm{dBm}(250 \mathrm{~mW})$, this study recommends small antennas with a power of at least $24 \mathrm{dBm}$ every $500 \mathrm{~m}$ for the intended coverage area desired by the $5 \mathrm{G}$ telecom operator(s).

\section{CONCLUSION}

This study compares and discusses three (3) different path reduction factor models. The essence of the reduction factor is either to reduce the point rain rate to the path averaged rain rate, or to reduce the actual path length filled with the uniform point rainfall. Several models have been proposed by researchers to account for the horizontal variation of rainfall. However, the ITU-R model is still the most widely used model for rain attenuation predictions in a tropical location. Attenuation caused by rain on a millimeter-wave link faces a tremendous challenge to signal accessibility for $5 \mathrm{G}$ networks operating in tropical locations. Different models are proposed to predict attenuation due to precipitation, however recent models show considerable discrepancies with predictions for short-range path lengths especially from $100 \mathrm{~m}$ to $1000 \mathrm{~m}$.

The path reduction factor is the most important parameter in the prediction models for estimating total attenuation from specific attenuation. The models tested were proposed by [10], [12], and [21]. For path lengths less than $1 \mathrm{~km}$, it is observed that the path reduction factor is almost constant at 0.357 for the Ghiani model while it shows the value of $r$ decreasing exponentially with an increase in path length for the Budalal model. The ITU-R P.530-17 model however shows that the value of $r$ almost linearly decreases with an increase in path length. A comparison was made between the attenuation values predicted by these models for a $24.25 \mathrm{GHz}$ link for link lengths ranging from $100 \mathrm{~m}$ to $1 \mathrm{~km}$. Results indicate that the ITU-R and Budalal model predicted an attenuation ranging from $1.34 \mathrm{~dB}$ to $9.07 \mathrm{~dB}$ across all four (4) stations while the Ghiani model predicted an attenuation which ranged from $0.05 \mathrm{~dB}$ to $3.37 \mathrm{~dB}$ across all stations considered. For a link length of $0.2 \mathrm{~km}$, both the ITU-R and Budalal model predict almost exact attenuation and distance factor values across all stations. Generally, all models are found to predict rain attenuation and distance factors values with considerable differences especially for link lengths above $300 \mathrm{~m}$. Further research on path reduction factor models for accurate estimation of attenuation due to rain on $5 \mathrm{G}$ mmWave links especially for link lengths below $1 \mathrm{~km}$ is recommended.

\section{ACKNOWLEDGMENT}

The authors would like to thank the Tropical Rainfall Measurement Mission (TRMM) and the Nigerian Meteorological Agency (NiMet) for making rainfall data readily available for this research.

\section{REFERENCES}

1. A. Al-Saman, M. Mohamed, Y. Ai, M. Cheffena, M. Azmi, and T. A. Rahman, "Rain Attenuation Measurements and Analysis at $73 \mathrm{GHz}$ E-Band Link in Tropical Region", IEEE Communications Letters, vol. 24, 2020, pp. 1368-1372.

2. L. Luini, G. Royeda, M. Zaffaroni, M. Costa, and G. Riva, "The impact of rain on short E-band radio links for $5 \mathrm{G}$ mobile systems: Experimental results and prediction models", IEEE transactions on antennas and propagation.vol 68, no. 4, pp. 3124-3134. 2020.

3. S. Livieratos and P. Cottis, "Rain attenuation along terrestrial millimeter wave links: A new prediction method based on supervised machine learning", IEEE Access. vol 7, pp.138745-138756. 2019.

4. A. Budalal, I. Rafiqul, H. Habaebi and T. Rahman, "The effects of rain fade on millimeter wave channel in tropical climate", Bulletin of electrical engineering and informatics. vol 8, no. 2, pp. 653-664. 2019.

5. D. Nandi and A. Maitra, "The effects of rain on millimeter wave communication for tropical region", URSI Asia-pacific radio science conference. pp. 3-5. 2019.

6. S. Ibraheem, A. Tharek, M. Rahman and A. Azmi, "Rain attenuation of millimeter wave above $10 \mathrm{GHz}$ for terrestrial links in tropical regions", Transactions on emerging telecommunications technologies. pp. 1-5. 2018.

7. J. Huang, I. Cao, Y. Raimundo, A. Cheema, and S. Salous, "Rain Statistics Investigation and Rain Attenuation Modeling for Millimeter Wave Short Range Fixed Links", IEEE Access. vol 7, pp. 156110-156120. 2019.

8. L. Luini, et al "The Impact of Rain on Short E-band Radio Links for 5G Mobile Systems: Experimental Results and Prediction Models", IEEE Transactions on Antennas and Propagation. pp. 1-7. 2019.

9. A. Yusuf, and T. Rahman, "Statistical evaluation of measured rain attenuation in tropical climate and comparison with prediction models", Journal of Microwaves, Optoelectronics and Electromagnetic Applications. vol 15, no. 2, pp. 123-134. 2016.

10. R. Ghiani, L. Luini, and A. Fanti, "A physically based rain attenuation model for terrestrial links", Radio Science. vol. 52, no. 8, pp. 972-980. 2017.

11. Recommendation ITU-R. P.838-3 Series, "Specific attenuation model for rain for use in prediction methods", Recommendation ITU-R $P$ 838-3, pp. 1-8. 2005.

12. Recommendation ITU-R P.530-17. Propagation data and prediction methods required for the design of terrestrial line- of-sight systems Series Radio wave propagation. Recommendation ITU-R P.530-17.pp. 1-13. 2017.

13. A. Faragó, P. Kántor and J. Bitó, "Rain Effects on 5G millimeter Wave ad-hoc Mesh Networks Investigated with Different Rain Models", Periodica Polytechnica Electrical Engineering and computer science. vol. 60, no. 1, pp . 44-50. 2016.

14. I. Shayea, T. Rah, A. Man, M. Azmi, R. Islam, M. Islam, "Real Measurement Study for Rain Rate and Rain Attenuation Conducted Over 26 GHz Microwave 5G Link System in Malaysia", IEEE Access. vol. 3536, pp. 1-21. 2018.

15. S. Shrestha, and D. Choi, "Terrestrial Physics Rain attenuation statistics over millimeter wave bands in South Korea", Journal of Atmospheric and Solar Terrestrial Physics.vol. 152, pp. 1-10. 2017.

16. E. Hong, S. Lane, D. Murrell, N. Tarasenko, and C. Christodoulou, "Terrestrial link rain attenuation measurementsat $84 \mathrm{GHz}$ ", United States National Committee of URSI National Radio Science Meeting. pp. 1-2. 2017.

17. P. Valtr, and P. Pecha, "Distance Factor in Rain Attenuation Predictions", 13th European Conference on Antennas and Propagation. pp. 1- 3. 2019.

18. F. Diba, M. Samad, D. Choi, "The Effects of Rain on Terrestrial Links at K, Ka and E-Bands in South Korea: Based on Supervised Learning", IEEE Access 9. pp. 1-28. 2021.

19. M. Samad, Abdus, F. Diba, and D. Choi, "A Survey of Rain Attenuation Prediction Models for Terrestrial Links: Current Research Challenges and State-of-the-Art", Sensors. pp. 1-18. 2021.

20. J. Chebil, and T. Rahman, "Development of 1 min rain rate contour maps for microwave applications in Malaysia Peninsula", Electronics Letters. vol. 35, pp. 1712-1774. 1999.

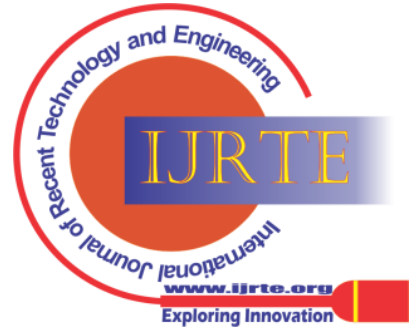




\section{Evaluation of Some Path Reduction Factor Models Performance in Tropical Location}

21. A. Budalal, M. Islam, K. Abdullah, and T. Rahman, "Modification of Distance Factor in Rain Attenuation Prediction for Short-Range Millimeter-Wave Links", IEEE Antennas and Wireless Propagation Letters. vol. 16, no. $9 . \quad$ pp. 1-5. 2020

22. F. Norouzian, E. Marchetti, M. Gashinova, E. Hoare, C. Constantinou, and P. Gardner, "Rain Attenuation at Millimeter Wave and Low-THz Frequencies", IEEE Transactions on Antennas and Propagation. pp. 1-8. 2019.

\section{AUTHORS PROFILE}

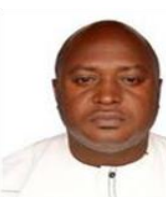

of the IEEE and ACM.
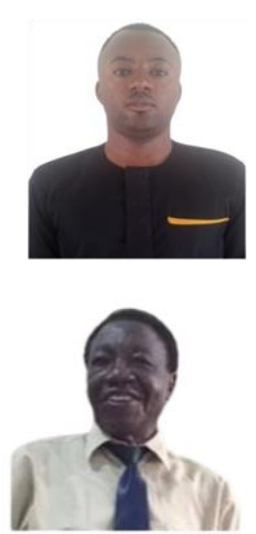

Gabriel Igwue is a Professor in the Department of Electrical and Electronics Engineering at Joseph Sarwuan Tarka University. He holds a Ph.D. from the North Caroline University, USA in Electrical engineering. He is a COREN registered engineer and a member of the Nigerian Society of Engineers

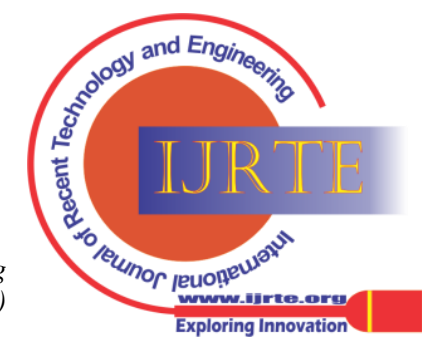

